\title{
ヒステリシスを考虑した円盤投の最適化
}

\author{
瀬尾 和哉 ${ }^{* 1}$, 下山 幸治 ${ }^{* 2}$, 木村 裕次 ${ }^{* 3}$, 太田 憲 ${ }^{* 4}$, 仰木 裕嗣 ${ }^{* 4}$
}

\section{The optimization study taking account of hysteresis in Discus}

\author{
Kazuya SEO ${ }^{* 1}$, Koji SHIMOYAMA ${ }^{* 2}$, Yuji KIMURA ${ }^{* 3}$, Ken OHTA $^{* 4}$ and Yuji OHGI ${ }^{* 5}$ \\ ${ }^{* 1}$ Yamagata Univ. Dept. of Education, Art and Science \\ Kojirakawa 1-4-12, Yamagata 990-8560, Japan
}

This paper describes the hysteresis in the aerodynamic properties of a discus near to its stalling angle. Wind tunnel tests were carried out with a full-size woman's discus. The experimental aerodynamic data D, L and M were obtained from wind tunnel tests as functions of the angle of attack. It was found that the drag, lift and pitching moment coefficients, $C_{D} C_{L}$ and $C_{M}$, increase with increasing the angle of attack up to a stalling angle of $30^{\circ}$. Beyond the stalling angle, $C_{L}$ and $C_{M}$ decrease suddenly and abruptly with increasing angle of attack. On the other hand, recovery from the stall does not occur at the same stalling angle of $30^{\circ}$ when the angle of attack decreases from the stall state; recovery actually occurs at $25^{\circ}$. The $\mathrm{C}_{\mathrm{L}}-\alpha$ (angle of attack) curve is almost the same when the angle of attack is less than $24^{\circ}$. Therefore, hysteresis occurs near the stalling angle.

Key Words : Discus, Hysteresis, Optimization

\section{1. 緒言}

円盤投研究の目的は，飛距離最長となる投出し条件を求めることである．この目的を達成する為には，3つの 行程が必要である. すなわち, 空気力測定 $\rightarrow$ 飛翔軌跡シミュレーションー最適化，である.これら一連の行程は， 報告済み(1)(2)であるが，今回，詳細に迎え角依存性を調べたところ，失速迎角近傍で，ヒステリシスが存在する 事が明らかになった．本報告では，ヒステリシスを含む空気力測定結果を使用しながら飛翔軌跡シミュレーショ ンをし，投げ出し条件最適化を実行した結果を報告する.

\section{2. 円盤に勄く空気力}

基本的な空力特性を知るために風洞実験により, 商用の女子用円盤（Discus SUPER for Women, Nishi）に働く空気力を計 測した(Figure 1). 風洞は，本実験室の低速風洞で，最大風速が $30 \mathrm{~m} / \mathrm{s}$, 乱れ度 $1.5 \%$ 以下である. 実験では, 風速を $15 \mathrm{~m} / \mathrm{s}$ から $30 \mathrm{~m} / \mathrm{s}$, 迎え角を $0^{\circ}$ から $90^{\circ}$ の範囲で変化させ, 円盤に働く抗力, 揚力, ピッチングモーメント（Figure 2）を計測した.

女子用円盤の測定結果を Figure 3 にしめした. 横軸は迎え角 $\alpha$, 縦軸は空力係数 $\left(C_{L}, C_{D}, C_{M}\right)$ である. 定義を式(1)と(2) に示した. 揚力係数 $C_{L}$ と抗力係数 $C_{D}$ は揚力 $L$ と抗力 $D$ 動圧と円盤平面面積 $A$ で除した值, ピッチングモーメント係数 $C_{M}$ はピッチングモーメント $M$ を動圧と $\mathrm{A}$ さらに円盤直径 $d$ で除した值である. 空力係数の風速や回転速度に対する依存性は小 さかった(1)ため, Figure 3〜 5には代表值として, 風速 $20 \mathrm{~m} / \mathrm{s}$, 回転速度 $0 \mathrm{rev} / \mathrm{sec}$.の場合を示した. また, 黒丸は迎え角を増加 させた場合の結果, 白三角は減少させた場合の結果である.

*1 正員, 山形大学 地域教育文化学部（广9990-8560 山形市小白川 1-4-12）

*2 正員, 東北大学 流体科学研究所

*3 正員, ニシ・スポーツ 開発部

*4 正員, 慶応義塾大学 大学院政策メディア研究科

E-mail: seo@e.yamagata-u.ac.jp

日本機械学会 [No.13-34] シンポジウム : スポーツ・アンド・ヒューマン・ダイナミクス 2013 講演論文集 [2013.11.1-3，東京] 
$C_{L, D}=\frac{L, D}{0.5 \rho U^{2} A}$

$$
C_{M}=\frac{M}{0.5 \rho U^{2} A d}
$$

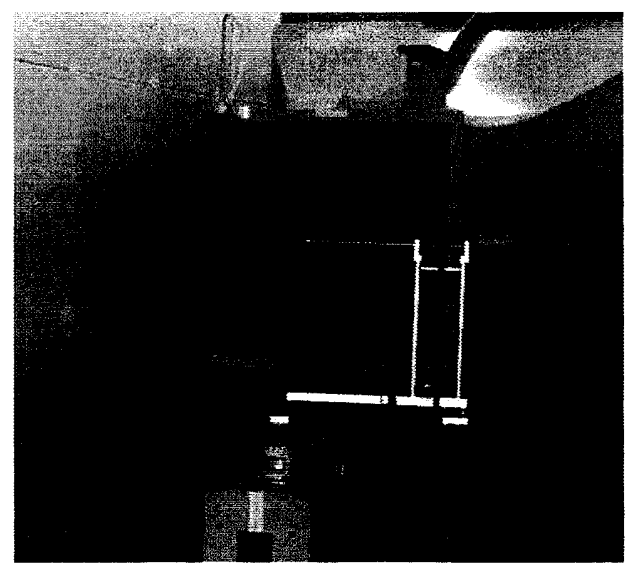

Figure 1 Experimental set-up

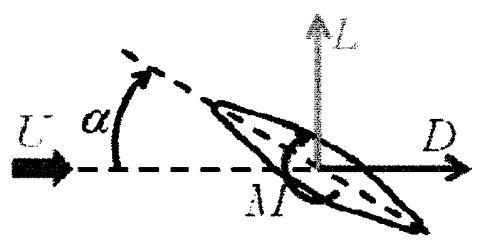

Figure 2 Definitions of characteristic parameters

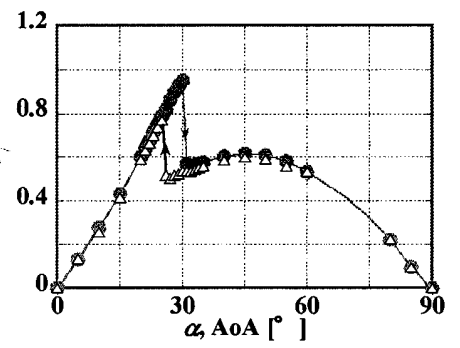

(a) The lift coefficient.

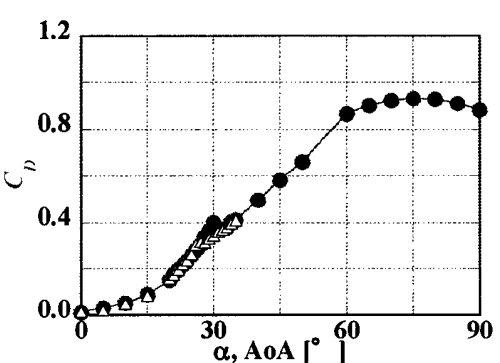

(b) The drag coefficient.

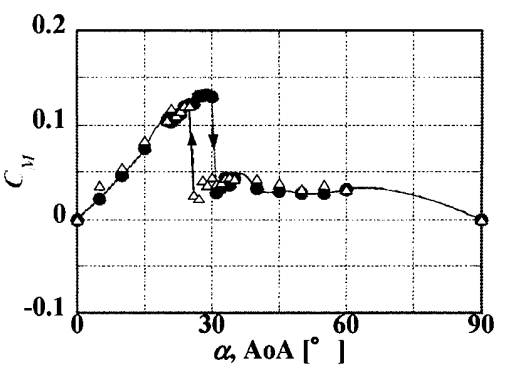

(c) The pitching moment coefficient.

Figure 3 Aerodynamic coefficients as a function of the angle of attack. The spin rate is 0 [rev./sec.].

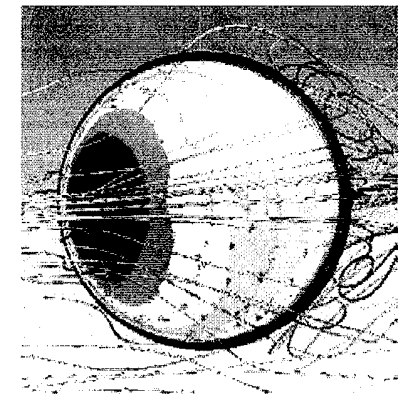

(a) The pressure side.

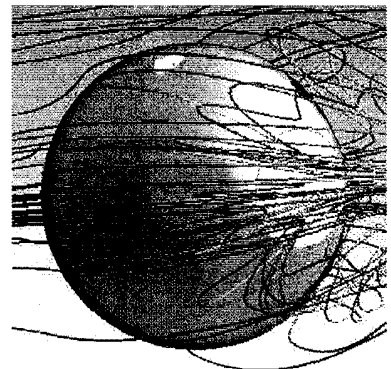

(b) The suction side.

Figure 4 Contour map of the pressure at $45^{\circ}$.

Figure 3-(a)より，揚力係数 $C_{L}$ は迎角 $\alpha$ とともに直線的に増加し，30 で最大值となる．この臨界角度を超え ると失速状態となり, $C_{L}$ は急減する. 揚力係数 $C_{L}$ は $45^{\circ}$ まで微増した後, 再び減少に転じ, $90^{\circ}$ で 0 になる. 90から $0^{\circ}$ への迎角隇少過程（ $\Delta$ 印）では，道筋が異なる．迎角増加過程とは異なり，30 では失速から回復 
せず，25で回復する． $25^{\circ}$ から $0^{\circ}$ への迎角減少過程では，迎角増加過程と道筋が重なる.よって， $C_{L} に は$ に, 失速近傍でヒステリシスが生じる. ピッチングモーメント係数 $C_{M}$ (Figure 3-(c)) にも同様のヒステリシス がある.ピッチングモーメントは, 実験した全領域で正，つまり頭上げであった. Figure 4 は CFD による迎角 $45^{\circ}$ の場合の圧力の等高線図である. 圧力側の等高線図が Figure 4-(a), 背面側の等高線図が Figure 4-(b)であ る. CFDには ANSYS の Design Modeler, Meshing, Fluent を使用した. 円盤の周りに円盤直径の 50 倍の立方

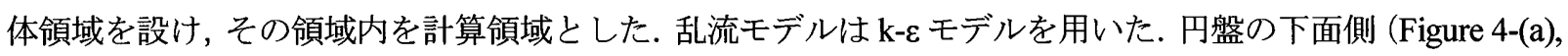
圧力側）は，円盤の前縁に近いほど圧力が高い. 一方，上面側（Figure 4-(b), 背面側）は，全面にわたりほ ぼ同じ圧力である．よって， 円盤上下面での圧力差は前縁近傍の方が大きくなる．この結果， $\alpha=45^{\circ}$ で頭 上げのモーメントが働く. 円盤の前縁で圧力が高くなる理由は, 円盤投用円盤の形による. 円盤は平らな円 板ではなく, 傾斜がある. この傾斜の為, 前縁近傍と後縁近傍では, 実効的な迎角が異なる. この結果, 前 縁に近い側は，圧力がより上昇する．その結果，Figure 4-(a)に示した圧力分布になると考える.

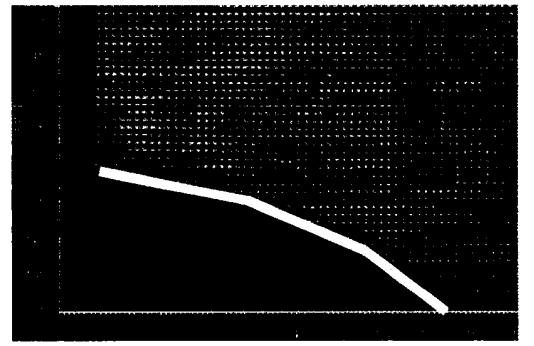

(a) $25^{\circ}$ in the process of increasing $\alpha$.

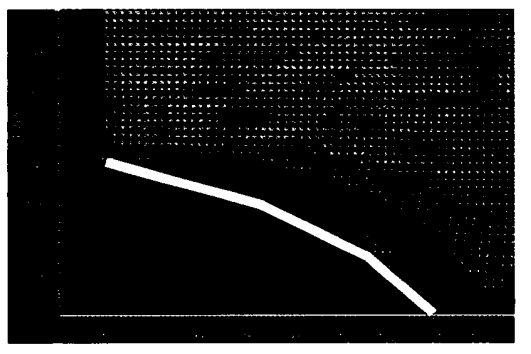

(d) $28^{\circ}$ in the process of decreasing $\alpha$.

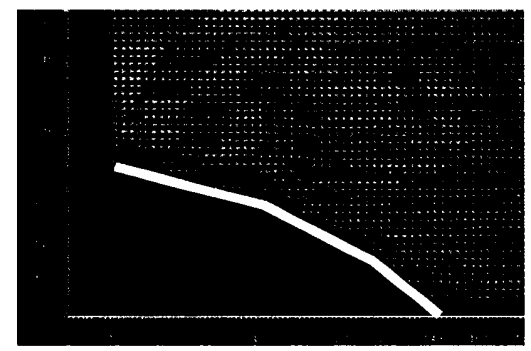

(b) $28^{\circ}$ in the process of increasing $\alpha$.

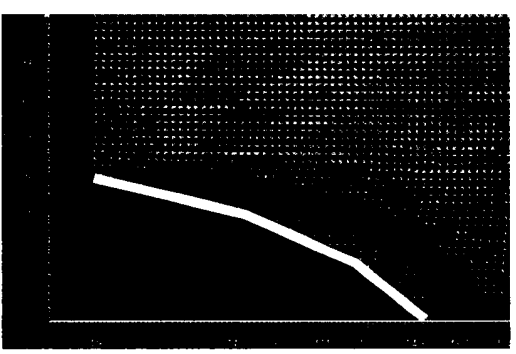

(e) $26^{\circ}$ in the process of decreasing $\alpha$.

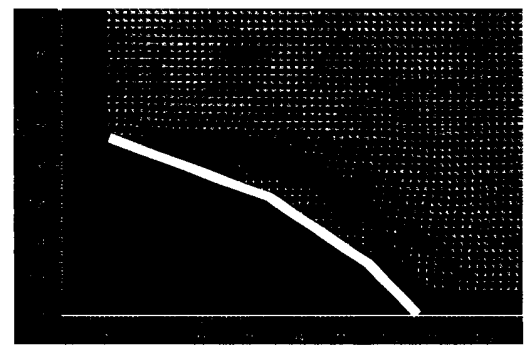

(c) $35^{\circ}$ in the process of increasing $\alpha$.

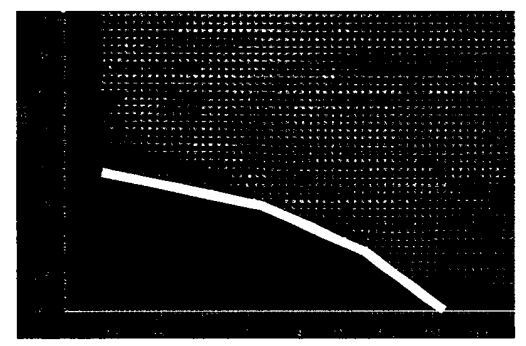

(f) $25^{\circ}$ in the process of decreasing $\alpha$.

Figure 5 2D-PIV measurements on the centerline of the discus.

Figure 5 は円盤背面側の PIV 計測結果である. Figure 5-(a)から(c)は迎角増加過程の速度ベクトル図, Figure 5-(d) から(f)は迎角減少過程の速度ベクトル図である. 1000fps の高速度カメラで 1 秒間測定し, その時閒平均をとった. 円盤は各図の下方に位置している，迎角増加過程の $25^{\circ}$ (Figure 5-(a))と $28^{\circ}$ (Figure 5-(b) )では，流れはほぼ円盤 背面に沿っている. 前縁下流側では, 速度の遅い領域がある. この領域は, 層流剥離泡が形成されている. 再付 着は, 円盤の凸近傍で起こっている. 一方, 迎角増加過程の $35^{\circ}$ (Figure5-(c))では, 再付着することなく, 境界層 がはく離している. 迎角減少過程の $28^{\circ}$ (Figure 5-(d))と $26^{\circ}$ (Figure 5-(e))では, 迎角増加過程の 35 (Figure 5-(c)) と同样に境界層が剥離している. 迎角減少過程の $25^{\circ}$ (Figure 5-(f))では, 失速状態から回復している.

\section{3. 最適化}

\section{$3 \cdot 1$ 目的関数}

慣性座標系を Figure 6 に示した. 原点を投出しサークル中心，前進方向を $X_{E}$, 横方向を $Y_{E}$ ，鉛直下方を $Z_{E}$ と した. 最適化の目的関数は, 飛距離である. 飛距離は長いほど良い. 飛距離はFI として, 式 (1)の通りに定義 した. 


$$
F 1=-\sqrt{X_{E}(t f)^{2}+Y_{E}(t f)^{2}}
$$

ここで, $t f$ は飛翔時間である. 式(1)の右辺にある $X_{E}(t)$ と $Y_{E}(t)$ は, 運動方程式等の数值積分により, 求められる. その際, 実験により測定した空力係数を参照する. 今回は, Figure 3 で示したヒステリシス有の空力係数を用い, 飛翔軌跡を計算した. 最適化は, 領域適応型遺伝的アルゴリズム（ARMOGA）(2)で行った. 人口を 300 , 世代を 300 とした.

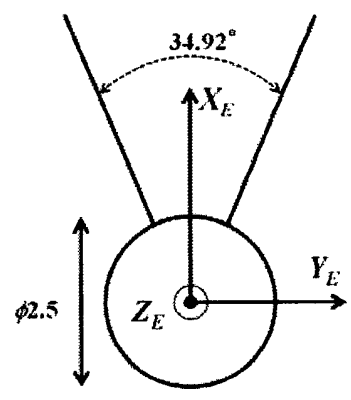

Table 1 Control variables

\begin{tabular}{|l|l|l|}
\hline$\#$ & 記号 & 最適化範囲 \\
\hline 1 & $\gamma_{0}$ & $15 \sim 60^{\circ}$ \\
\hline 2 & $\chi_{0}$ & $-30 \sim 30^{\circ}$ \\
\hline 3 & $\Psi_{0}$ & $-45 \sim 45^{\circ}$ \\
\hline 4 & $\Theta_{0}$ & $-60 \sim 60^{\circ}$ \\
\hline 5 & $\Phi_{0}$ & $-45 \sim 45^{\circ}$ \\
\hline 6 & $P_{0}$ & $-3 \sim 3 \mathrm{rev} . / \mathrm{sec}$. \\
\hline 7 & $Q_{0}$ & $-3 \sim 3 \mathrm{rev} . / \mathrm{sec}$. \\
\hline 8 & $R_{0}$ & $0 \sim 7 \mathrm{rev} . / \mathrm{sec}$. \\
\hline 9 & $I_{S}$ & $0.0055 \sim 0.006 \mathrm{~kg} \mathrm{~m}$ \\
\hline 10 & $m_{d}$ & $1.005 \sim 1.025 \mathrm{~kg}$ \\
\hline
\end{tabular}

Figure 6 Inertial coordinate system.

\section{$3 \cdot 2$ 制御変数}

制御変数は, Table 1 に示した 10 個ある. \#1〜8 は投出しのスキルに関わる制御変数，\#9\&10はもものづくりに関 わる設計変数である. これらを並行して, 最適化する. 投出しスピードは $26 \mathrm{~m} / \mathrm{s}$, 投出し位置は $\left(X_{E}, Y_{E}, Z_{E}\right)=$ (1.0,1.0,-1.6) とした. \#1\&2 は速度ベクトルの方向，\#3〜5 はオイラー角で慣性座標系に対する円艋姿勢を表す 角度, \#6 8 は角速度ベクトル，\#9 は回転対称軸周りの慣性モーメント，\#10 は円盤質量である. ARMOGA の際 に各変数がとりうる範囲を最適化範囲として, Table 1 に示した.

\section{$3 \cdot 3$ 結果}

最適フライトを Figure 7 に示した. 飛距離は約 $80 \mathrm{~m}$ である. 0.7 秒ごとの円盤の姿勢と速度ベクトル (赤矢印), 揚力ベクトル (青矢印), 抗力ベクトル (黄色ベクトル) を示した。投出し時(Figure 7-(a))には, 風が円盤上方か ら吹き込むため, 揚力は下方に働く，これは飛距離を短くする要素である. しかし, 重要なことは, 飛翔前半に 抗力を小さくすることである. 投出し時に傾いていた円盤は飛翔の後半になるとほぼ水平になる. この水平姿勢 は，飛翔後半で円盤が落下寸ることを防ぐ効果がある.

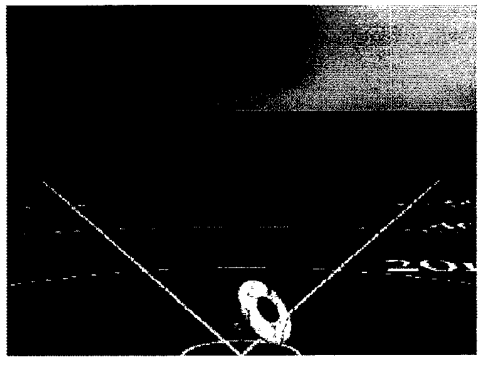

(a) Osec.

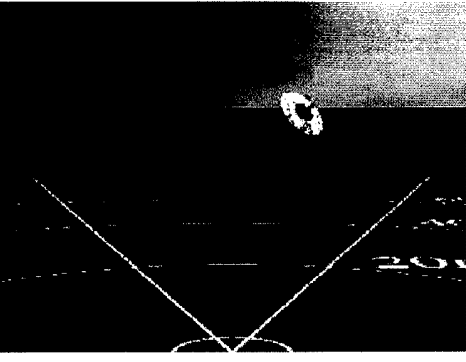

(b) $0.7 \mathrm{sec}$

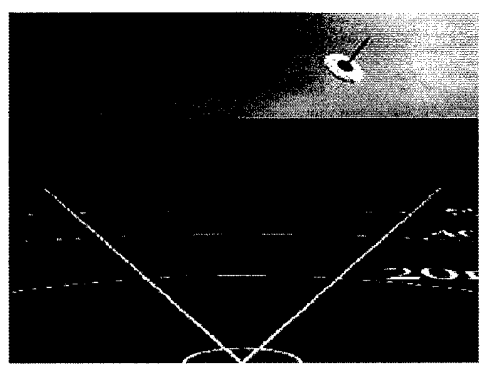

(c) $1.4 \mathrm{sec}$. 


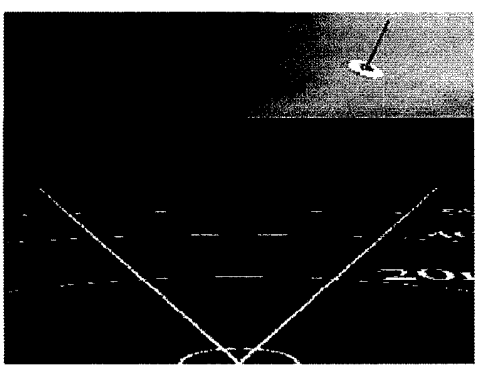

(d) $2.1 \mathrm{sec}$.

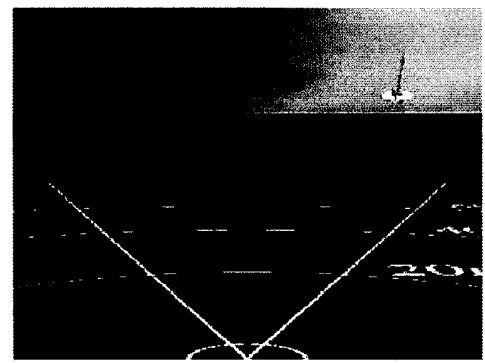

(e) $2.8 \mathrm{sec}$.

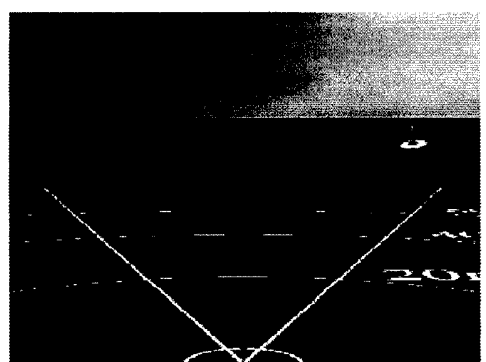

(e) $3.5 \mathrm{sec}$.

Figure 7 Optimal flight from the back view.

\section{4. 結 語}

（1）揚力係数とピッチングモーメント係数の迎角依存性には，ヒステリシスがある.

（2）迎角を $0^{\circ}$ から増加させた場合， $30^{\circ}$ で失速する，迎角を $90^{\circ}$ から減少させた場合，失速から $25^{\circ}$ で回 復する.

（3）ピッチングモーメント係数は， $0^{\circ}$ から $90^{\circ}$ の範囲で常に正，つまり頭上げのモーメントになる.

（4）ヒステリシスを含む空力係数を用いて，最適フライトを求めたところ，飛距離は $80 \mathrm{~m}$ になった.

（5）最適フライトでは，円盤は傾いて投出されるが，飛翔の後半にはほ水水平になる.

（6）最適フライトでは，投出し時に円盤に対して上方から風が流入する.

\section{謝辞}

本研究は，科学研究費補助金（基盤研究（A）No.23240090）の助成を受けた．感謝の意を表する.

\section{文献}

(1) Seo, K., Shimoyama, K., Ohta, K., Ohgi, Y. , Kimura, Y. , “Aerodynamic behavior of a discus", Procedia Engineering 34, Vol.34 (2012) pp.92-97.

(2) Seo, K., Shimoyama, K., Ohta, K., Ohgi, Y., Kimura, Y. , "Optimization of the moment of inertia of a disc and the release condition of a discus", Procedia Engineering 34, Vol.34 (2012) pp.170-175. 